\title{
Development of an instrument to measure organisational culture in community pharmacies in Great Britain
}

DOI:

10.1108/JHOM-06-2017-0131

\section{Document Version}

Accepted author manuscript

Link to publication record in Manchester Research Explorer

\section{Citation for published version (APA):}

Marques, I., Willis, S., Schafheutle, E., \& Hassell, K. (2018). Development of an instrument to measure organisational culture in community pharmacies in Great Britain. Journal of Health, Organization and Management, 32, 176-189. https://doi.org/10.1108/JHOM-06-2017-0131

\section{Published in:}

Journal of Health, Organization and Management

\section{Citing this paper}

Please note that where the full-text provided on Manchester Research Explorer is the Author Accepted Manuscript or Proof version this may differ from the final Published version. If citing, it is advised that you check and use the publisher's definitive version.

\section{General rights}

Copyright and moral rights for the publications made accessible in the Research Explorer are retained by the authors and/or other copyright owners and it is a condition of accessing publications that users recognise and abide by the legal requirements associated with these rights.

\section{Takedown policy}

If you believe that this document breaches copyright please refer to the University of Manchester's Takedown Procedures [http://man.ac.uk/04Y6Bo] or contact uml.scholarlycommunications@manchester.ac.uk providing relevant details, so we can investigate your claim.

\section{OPEN ACCESS}




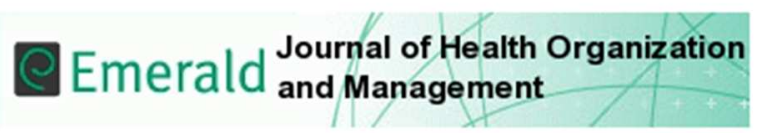

\section{Development of an instrument to measure organisational culture in community pharmacies in Great Britain}

\begin{tabular}{|r|l|}
\hline Journal: & Journal of Health Organization and Management \\
\hline Manuscript ID & JHOM-06-2017-0131.R2 \\
\hline Manuscript Type: & Original Article \\
\hline Keywords: & Organisational Culture, Community Pharmacy \\
\hline \multicolumn{2}{l}{} \\
\hline
\end{tabular}

SCHOLARONE $^{m}$
Manuscripts 


\title{
Development of an instrument to measure organisational culture in community pharmacy in Great Britain
}

\begin{abstract}
Purpose - Organisational culture (OC) shapes individuals' perceptions and experiences of work. However, no instruments capable of measuring specific aspects of $\mathrm{OC}$ in community pharmacy exist. This paper reports the development and validation of an instrument to measure $\mathrm{OC}$ in community pharmacy in Great Britain (GB), and preliminary analysis of data collected using it.

Methodology - Instrument development comprised three stages: I: 12 qualitative interviews and relevant literature informed instrument design; II: 30 cognitive interviews assessed content validity; III: a cross-sectional survey mailed to 1000 community pharmacists in GB, with factor analysis for instrument validation. Statistical analysis investigated how community pharmacists perceived $O C$ in their place of work.
\end{abstract}

Findings Factor analysis produced an instrument containing 60 items across five OC dimensions - Business and work configuration, Social relationships, Personal and professional development, Skills utilisation, and Environment and structures. Internal reliability for the dimensions was high (0.84 to 0.95); item-total correlations were adequate $(r=0.46$ to $r=0.76)$. Based on two-hundred-and-nine responses, analysis suggests different OCs in community pharmacy, with some community pharmacists viewing the environment in which they worked as having a higher frequency of aspects related to patient contact and safety than others. Since these aspects are important for providing high healthcare standards, it is likely that differences in OC may be linked to different healthcare outcomes.

Originality/value - This newly developed and validated instrument to measure OC in community pharmacy can be used to benchmark existing OC across different pharmacies and design interventions for triggering change to improve outcomes for community pharmacists and patients.

Keywords - Organisational culture, Community Pharmacy

Paper type - Research paper 


\section{Introduction}

Over the last 30 years, organisational culture (OC) has become an increasing focus of healthcare research, as it appears to be linked to the delivery of care, patient safety and job performance (Konteh et al., 2011). Organisational culture can be defined as the set of values, beliefs and behaviours people adopt at the workplace, based on what is considered to be common practice, shaping individuals' work perceptions and experiences (Schein, 1990). More specifically, OC relates to individuals' experiences and perceptions of their workplace, and it is considered that success can be driven by understanding the culture, or what values, beliefs and behaviours are prevalent in an organisation (Handy, 1993). Schein argued that OC is learnt by exposure to the work environment, and is divided into three layers: Observable artefacts (observable, behaviours representing the consequence of deeper layers); espoused values (values shared by individuals shaping their attitudes), and underlying basic assumptions: invisible influencers of the first two layers, that can only be measured indirectly through the measurement of the behaviours (first layer) and attitudes (second layer) (Schein, 1990). Its influence on how individuals act and react, and understand their environment and others (Helms and Stern, 2001), makes it important to investigate how OC is perceived (Handy, 1993). For this reason, OC has become the focus of the National Health Service (NHS) in general (Konteh et al., 2011) and community pharmacy in particular (Scahill, 2008) as a means to improve the delivery of healthcare.

Organisational culture has also been shown to mediate the relationship between leadership and job performance (Ogbonna and Harris, 2000). Additionally, when individuals perceive a high control over their work and support from their peers, their job performance improves (Nagami et al., 2010). The work environment, job control and organisational support also interact with cognitive variables, and may create cognitive tensions and distractions resulting in reduced ability to cope with workloads and substandard performance (Vischer, 2007), and low job satisfaction (Grasha and Schell, 2001).

In healthcare, research on poor performance and its negative impact on patient outcomes has highlighted the need to consider $\mathrm{OC}$ when investigating safety and 
performance; literature also shows that $\mathrm{OC}$ can be changed in order to improve patient outcomes (Kennedy, 2001, Scott et al., 2003b, Brown et al., 2015, Williams et al., 2015). With different types of culture linked to different levels of performance and patient safety (Scott et al., 2003b), OC, if addressed and improved, has been shown to have a positive impact on performance and patient safety (Carlström and Ekman, 2012, Kaufman and McCaughan, 2013, Brown et al., 2015, Terzioglu et al., 2016).

\section{Organisational Culture in community pharmacy}

As healthcare delivery shifts from secondary to primary care, community pharmacies are playing a bigger role in healthcare. They provide public health additional medicines services (particularly for patients with long-term conditions), such as medicines use reviews (MURs) alongside their more traditional medicines supply function (Pharmaceutical Services Negotiating Committee, 2017)(Pharmaceutical Services Negotiating Committee, 2017)(Pharmaceutical Services Negotiating Committee, 2017)(Pharmaceutical Services Negotiating Committee, 2017). Whilst allowing community pharmacists to use their clinical skills more effectively, the introduction of these additional nationally funded NHS services has increased community pharmacists' workload (Hassell et al., 2011). However, there is evidence that this impact differs depending on ownership type (Bradley et al., 2008), with pharmacies ranging from those owned by pharmacists through medium to large chains and supermarket pharmacies in corporate ownership, and where pharmacists may work as employees or an a self-employed sessional basis as locums. Organisational priorities and cultures are therefore likely to vary across different ownership configurations as well as between individual community pharmacies. However, it is unclear how the different cultures may influence outcomes for both pharmacists and patients.

In community pharmacy, understanding of, and research into, OC is limited. A literature review of studies focusing on organisational variables identified five themes of OC: business orientation in each pharmacy (that is, whether targets or patients are prioritised by the business), management and communication style, peer support, autonomy, professional values and attitudes and organisational change and their association with job and pharmacist-related outcomes (Jacobs et al., 2011). 
The authors found a link between organisational variables and job satisfaction and commitment, quality of care, patient satisfaction and safety. Additionally, in a study about safety climate in community pharmacies, Phipps and Ashcroft (Phipps and Ashcroft, 2011), linked different organisational configurations to different job outcomes (e.g. safety incidents such as dispensing errors), again suggesting that different cultures are important in explaining differences in outcomes. Given the findings from these studies, it is important to understand $\mathrm{OC}$ in community pharmacy in more detail. However, to date, studies have focused on isolated aspects of $O C$ and no studies have investigated $\mathrm{OC}$ in community pharmacy in Great Britain (GB) specifically. Nevertheless 70 instruments measuring OC exist (Jung et al., 2009), but none have been validated for the community pharmacy context. Of the instruments available, two are widely used: the Organisational Culture Assessment Instrument (OCAI) and the Organisational Culture Inventory (OCI) (Bellot, 2011). These two instruments allow for cultural comparisons across settings, and assume that all cultures consist of the same domains and can be measured using the same tool. While these instruments have proved valuable in the measurement of organisational culture, they lack the level of detail required to develop targeted improvement interventions because they lack context-specificity (Scott et al., 2003a) (Druckman et al., 1997). For example, in relation to the theoretical dimensions of OC identified by Jacob and colleagues (Jacobs et al., 2011), generic instruments such as the $\mathrm{OCl}$ and OCAI would be able to capture aspects of social relationships and autonomy (Workload, management style, social support and autonomy) or aspects driving the business forward (Entrepreneurial orientation); however, they would fail to detect the business priorities of a pharmacy (e.g. whether targets or patients are prioritised by the business, Professional-business role dichotomy), or issues relating to the dispensing of medicines or provision of services and aspects of a store's physical environment (Professional culture), which have been shown previously as relevant to understanding $\mathrm{OC}$ in community pharmacy. Hence, a new instrument is required, based on empirical investigation of organisational characteristics relevant to the measurement of $\mathrm{OC}$ and in community pharmacy, with verifiable statistical and predictive power to establish their link to different outcomes. Such an instrument could then be used to design interventions to improve culture in community pharmacy and associated outcomes. 
Aim

The aim of this paper is two-fold: firstly, to report on the development and validation of a new instrument capable of capturing specific aspects of $\mathrm{OC}$ in community pharmacy and discriminating between different cultures existing in pharmacies in GB (primary aim); and secondly, to provide some preliminary insights into how community pharmacists perceive their OC based on analysis of survey data collected using this new instrument (secondary aim).

\section{Method}

Instrument development and validation involved three stages:

I. Identification of themes and drafting of instrument items, using existing literature and qualitative interviews with community pharmacists;

II. Qualitative validation of the content of the instrument using cognitive interviews;

III. Quantitative validation of the instrument items using responses obtained from community pharmacists in Great Britain to a cross-sectional survey.

The secondary aim of this paper, to present findings related to community pharmacists' perceptions of $\mathrm{OC}$, has also been addressed using quantitative analysis of responses to the same survey.

University ethics approval was granted for each stage of the work.

\section{Stage I: Identification of themes and drafting of instrument items}

Twelve semi-structured qualitative interviews were conducted with a convenience sample of community pharmacists working in Greater Manchester. Participants were identified and recruited using the snowball sampling method. Initially, community pharmacists known to the first author were approached and invited to take part. Those who agreed to participate in a one-to-one semi-structured interview were asked to recommend other potential participants. Despite using the snowballing 
method, the authors ensured that the sample of participants used for this stage included a wide range of community pharmacists from different backgrounds, ethnicities, job roles and pharmacy types, to ensure maximum representative of findings. Participants were provided with information sheets and written consent was sought from all community pharmacists who agreed to participate, before the interviews took place. Interviews originally explored work conditions, the workplace, relationships, colleagues and managers, and how workload is managed, to investigate: (1) participants' work perceptions and experiences in community pharmacy; (2) organisational characteristics describing "the way things are done within an organisation" (Schein, 1990); 3) uncover the behaviours required to fit in and meet the expectations of the organisation (that is, its behavioural norms).To accomplish this, participants were asked questions about their perceptions and expectations of work, control over work and work pressures, patient contact, rules and policies, organisational priorities, social relationships, and opportunities for training and promotion. Thematic analysis of interview transcripts was subsequently conducted in NVivo(C) to identify organisational characteristics described by pharmacists as present within the organisation where they worked. Analysis of findings revealed behaviours, beliefs and attitudes described by the participants that seemed to influence the way they conducted their work and perceived their environment. For example, one pharmacist working in two pharmacies reported that the amount of work differed in each pharmacy, but because there was a greater culture of support within the pharmacy with a higher amount of work, this pharmacist felt it was easier to cope with her workload than in the pharmacy with noticeably less pressurised workload. In other words, findings revealed observable artefacts and espoused values which seemed to underlie basic assumptions and influence work outcomes (Schein, 1990). For this reason, the authors decided to explore OC further, by identifying themes pertaining to aspects of $\mathrm{OC}$ based on observed behaviours, beliefs and attitudes described by participants. These themes would serve as the basis for the design of a new instrument to measure $\mathrm{OC}$ in community pharmacy. To accomplish this, the authors extracted statements pertaining to aspects of pharmacists' workplace from participants' quotes and categorised them into themes (Table 1). To ensure statements (i.e. future instrument items) were relevant in describing characteristics of $\mathrm{OC}$ in community pharmacy, they were mapped to the theoretical dimensions of $\mathrm{OC}$ in community pharmacy summarised by Jacobs and 
colleagues (2011). Based on this analysis, the authors identified 17 emerging themes relevant to capturing aspects of $\mathrm{OC}$ in community pharmacy.

\author{
$<$ Insert Table 1 here $>$
}

One hundred and forty-four instrument items were drafted using interview participants' quotations coded as related to one of the 17 themes identified through analysis of the transcripts. Instrument items were not reproduced verbatim from participants' quotations; instead, they were drafted in the third person as examples of organisational characteristics described in the interviews as having an effect on how work was organised or experienced in a community pharmacy work setting (e.g. "To provide services that put you in contact with patients").

Besides using items generated during interviews relevant literature (Bryman, 2006, O'Cathain et al., 2008) was also used to generate further instrument items. Here, the narrative review by Jacobs et al. about $\mathrm{OC}$ in community pharmacy (Jacobs et al., 2011) provided the starting point for the identification of relevant papers, and the reference lists of these relevant papers then used to identify further papers. This was to ensure that other aspects which may have not been explored in the interviews but may still be relevant in describing $\mathrm{OC}$ in community pharmacy were included. Publications by (Tann et al., 2001, Pioch and Schmidt, 2001, Roberts et al., 2005, Hopp et al., 2005, Jambulingam et al., 2005, Perepelkin and Findlay, 2009) resulted in a 58 further items being drafted, giving a total of 202 items.

Before validation of these items in Stage II, it was important to choose a response scale for the instrument. In order to explore the nature and extent to which any item might be perceived as present in an organisation, a five-point rating scale was selected, ranging from 1 (Never) to 5 (Always) (Smith, 2002). This allowed for items to capture the frequency with which a characteristic was considered present in a work setting, consistent with our approach to measuring $\mathrm{OC}$ as a set of underlying behavioural norms related to how employees are expected to approach their work and interact with each other; similar response scales are also used by other OC instruments (Schinka et al., 2003, Cameron and Quinn, 2005). 
Stage II: Qualitative validation using cognitive interviews

The second stage of instrument development and validation involved cognitive interviews. Cognitive interviews are a technique which allows for the investigation of participants' real-life experiences of their work, by asking them to describe (i.e. thinkaloud) recent examples that asserted the relevance of each instrument item (Fowler Jr, 1995). Undertaking cognitive interviews was an essential step to ensure each instrument item described aspects of OC in community pharmacy, whilst also allowing the identification of other aspects which may have not been identified during the qualitative interviews in Stage I. Asking participants to verbalise their experiences also allowed the investigation of issues of understanding and clarity of each instrument item, as well as what information participants recalled when answering each item (Groves et al., 2009).

A convenience sample of pharmacy practice researchers $(n=8)$ and community pharmacists $(n=6)$ known to the first author were invited to take part in a cognitive interview. Similarly to stage I, the authors strived to include participants ranging in terms of job role, experience, ethnicity and pharmacy type to ensure maximum representativeness of findings. Instrument items interpreted by participants as having the same meaning as each other were combined into a single item or excluded. Ambiguous items were reworded based on participants' suggestions. Items worded negatively were reworded so that each item would work better with the chosen response scale measuring the frequency with which an aspect of $\mathrm{OC}$ was perceived as present in a work setting. Instrument items originally drafted in the third person were rewritten in the first person, again in order to work better with the chosen response scale (e.g. "To receive constructive feedback about your work" was reworded to "I receive constructive feedback about my work"). As a result of this process the number of items was reduced from 202 to 108.

In addition to validating the individual items, participants were asked to consider the number of items included and the appropriateness of the response scale. All participants reported that the length of the instrument was acceptable, and the rating scale chosen captured the frequency with which each OC characteristic was present 
in their workplace. Analysis of responses provided by participants also revealed that the rating scale chosen was sensitive to measuring variability between workplaces.

Following this, 30 cognitive interviews were conducted with a convenience sample of 17 community pharmacists working in the North of England. The first author recruited participants at community pharmacy continuing education events and using snowball sampling. In this phase of the qualitative validation, each item was presented to participants in the form of a flash card. The relevance of each item to the measurement of $\mathrm{OC}$ in community pharmacy was investigated (face validity) by exploring what each item meant to participants based on their own practice experience. Further issues of clarity and ambiguity were resolved, and participants were asked to identify aspects of their workplace corresponding to their behaviours, beliefs and attitudes which had not been explored. However, no further item exclusions or additions occurred, with participants reporting that all 108 instrument items were relevant to capturing aspects of $\mathrm{OC}$ based on their experience of pharmacy practice.

\section{Stage III: Quantitative validation}

Quantitative validation using SPSS $\odot$ v22 involved data analysis of responses to a cross-sectional postal survey sent to a random sample of 1000 community pharmacists working in small, medium and large chains, independent and supermarket pharmacies in Great Britain (GB), using premises addresses provided by the pharmacy regulator, the General Pharmaceutical Council. Exploratory factor analysis using Principal Axis Factoring with oblique rotation was conducted to test the component structure of the instrument and optimise its length. This process allowed for the identification of different dimensions of $\mathrm{OC}$ in community pharmacy in $\mathrm{GB}$ and for identification of the individual items within these dimensions. Internal reliability and construct validity were investigated by conducting Cronbach's alpha tests for the overall instrument and individual scales to assess internal consistency. Item-total correlations were then calculated to investigate the extent to which instrument items measure different characteristics of the same dimension (homogeneity criteria) (DeVellis, 2012). 
Finally, to address the secondary aim of this paper, statistical tests were applied to survey responses to provide a preliminary investigation of $\mathrm{OC}$, using data related to a respondent's workplace (i.e. pharmacy type and job role) and pharmacist characteristics (i.e. age, ethnicity and years of experience). To make comparisons between domains of $\mathrm{OC}$ identified by the quantitative validation described above, total mean scores for the overall instrument and each scale (i.e. dimension) were calculated. A maximum mean score obtained by summating all the items of the instrument or scale and dividing by the total number of items, was calculated to determine the total mean score in ideal conditions (i.e. conditions described by all items that are always present). Differences in total scores represent differences in terms of frequency with which items are present in the OC of a particular setting (i.e. current OC). These were then compared across settings. To further establish possible perceived differences in terms of the extent to which aspects of OC were present in the respondents' workplace, inferential tests were conducted, such as chisquares, independent samples t-tests, one-way ANOVAs and multiple regression analysis.

\section{Results}

After presenting a summary of the characteristics of survey respondents, findings are presented in two sections: section I focuses on the quantitative validation and final structure of the instrument; section II presents the results from the preliminary analysis of the data collected by the instrument.

\section{Survey respondents}

Two-hundred-and-nine surveys were returned, giving a response rate of $20.9 \%$. The majority of respondents were female $(50.7 \%)$, white $(51.6 \%)$ with up to five years of experience $(27.3 \%)$, working in chain pharmacies $(71.2 \%)$ and as store managers $(60.8 \%)$. A large proportion of respondents reported working as the only pharmacist $(66.5 \%)$. These respondent characteristics are comparable to those of previous workforce censuses, suggesting good representativeness of the respondents (Seston and Hassell, 2009, Phelps et al., 2014). 


\section{I: Quantitative validation and final structure of the 'Organisational Culture in Community Pharmacy Questionnaire' (OCCPQ)}

Exploratory factor analysis identified 48 items for exclusion for being poor predictors of $\mathrm{OC}$. The final instrument consisted of 60 items organised across five dimensions: Business and work configuration; Social relationships; Personal and professional development; Skills utilisation; and Environment and structures. These dimensions were defined and described based on their item loadings and associations with the 17 themes of OC presented earlier (Table 1). These themes describe organisational aspects community pharmacists perceived as important to ensure good workflow and delivery of the highest standard of patient care (Table 2).

\section{$<$ Insert Table 2 here $>$}

\section{Psychometric properties of the instrument}

Factor analysis identified a five factor solution (five dimensions of $\mathrm{OC}$ ) explaining $53.34 \%$ of the common variance. The instrument demonstrated good psychometric properties. Internal reliability of each of the scale dimensions was high, well above the criteria of $>0.7$ (Streiner and Norman, 2008). Internal reliability for the overall instrument was also high (Cronbach's $\alpha$ of 0.97 ). Item-total correlations ranged from $r=0.46$ and $r=0.76$, within the established criteria of $r>0.3$ and $r<0.9$ (Streiner and Norman, 2008). These values show that all instrument items measure the same construct (i.e. OC in community pharmacy) and perform well in measuring different concepts or dimensions within the construct. The instrument is therefore capable of capturing differences reflecting true relationships between the variables (Table 3 ).

$$
\text { <Insert Table } 3 \text { here }>
$$

II: Preliminary analysis of data collected by the 'Organisational Culture in Community Pharmacy Questionnaire' (OCCPQ)

The overall mean score for $\mathrm{OC}$ in community pharmacy was $\mathrm{M}=3.70(\mathrm{SD}=0.65)$. The subscale "Social relationships" produced the highest mean score $(M=4.05$, 
$S D=0.84$ ), indicating that relationships established in the workplace were most likely to have been perceived as present within an OC. The subscale "Personal and professional development" produced the lowest mean score $(M=3.31, S D=0.84)$, indicating that opportunities for training to improve knowledge and update skills, strategies to cope with change, feedback about work and career progression were less frequently reported as being present within a workplace.

Significant differences with a moderate effect size were found between pharmacy type and the subscale "Business and work configuration $(F(4,204)=5.640$, $\mathrm{p}=0.0003, \mathrm{\eta} 2=0.10)$, between independent pharmacies, large chains and supermarkets, and between small chains and supermarkets. These differences, also reported in the qualitative interviews, suggest that pharmacists working in independent pharmacies were more likely to have perceived their $\mathrm{OC}$ as valuing patients and their safety. Pharmacists working in supermarkets, on the other hand, were less likely to have reported their $\mathrm{OC}$ as frequently prioritising patient care over the business.

Significant differences with a moderate effect size were found between job role and the overall scale $(F(5,201)=3.381, p=0.006, \eta 2=0.08)$ and the subscales "Business and work configuration" $(F(5,201)=4.289, p=0.001, \eta 2=0.10)$ and "Environment and structures" $(F(5,201)=4.461, p=0.001, \eta 2=0.10)$. These two subscales were also highly correlated $(r=7.12, p<0.01)$, suggesting that pharmacists who perceived the $\mathrm{OC}$ of their pharmacy had some characteristics related to one domain, were likely to report that characteristics of the other domain were also present in their workplace. In this context, pharmacist owners were more likely to report items related to having a patient focus and patient safety as present in the $\mathrm{OC}$ of their workplace, followed by pharmacy managers (employee pharmacists managing their own pharmacy). Relief managers (pharmacists employed to provide cover at different stores within the same chain) were least likely to report items related to patient safety as occurring frequently in their workplace overall; second pharmacists (i.e. those who work alongside another pharmacist in the same pharmacy) reported the lowest frequencies for items related to the business orientation in their pharmacies. Regarding business orientation and patient safety, interview respondents linked 
lower levels of patient safety to environments prioritising business aspects (e.g. targets).

Significant differences with a moderate effect size were found between age groups and the subscale "Skills utilisation" $(F(4,173)=4.571, p=0.002, \eta 2=0.10)$, as well as years of practice $(F(9,193)=1.997, p=0.042, \eta 2=0.10)$, suggesting that older and more experienced pharmacists were more likely to have reported opportunities to utilise their clinical knowledge and skills as occurring frequently in their workplace. Significant differences with a small effect size were also found between white pharmacists and pharmacists from ethnic minority backgrounds $(M=3.48, S D=0.75)$ regarding the subscale "Personal and professional development" (t (203)=-2.001, $p=0.047,(n 2=0.02)$, suggesting that pharmacists from ethnic minority backgrounds were more likely to have reported that the OC of their workplace offered frequent opportunities for training to update their knowledge and skills, and providing new services to patients, compared to white pharmacists $(M=3.23, S D=0.88)$.

Multiple regression analysis did not reveal significant predictor models for the overall scale. However, in relation to the subscales, multiple regression indicated a significant model for the subscale "Business and work configuration" ( $F$ (40, $162)=1.502, p=0.04)$, with predictors explaining $29.0 \%$ of the total variance. These predictors were "Job role (Owner)" ( $\beta=0.234$ ) and "Years of experience (six to ten years)" ( $\beta=-0.216)$. The relationship between owners and this dimension suggests that owners reported aspects of the dimension as occurring more frequently in their workplace than store managers (the reference group). For example, qualitative interview respondents who were owners reported having more control over the staff and stock, as well as which services to make available to patients based on demand, compared to community pharmacists working in other settings.

On the other hand, pharmacists with six to ten years of experience reported aspects of this dimension as occurring relatively less frequently in their workplace compared to those with up to five years of experience (reference group). 


\section{Discussion}

Community pharmacy organisations are private sector providers of health services that range in organisational type from small owner run traders to large chains. As such, it is likely that they will have different business foci, priorities and goals, and also different organisational cultures influencing how pharmacists are expected to approach their work and interact with patients and their colleagues. In the absence of an instrument to measure $\mathrm{OC}$ in community pharmacy, the purpose of the study described here was to design and validate such an instrument capable of capturing specific aspects of OC in community pharmacy that would also discriminate between different cultures. This paper has reported on this process and presented findings from the use of this instrument with a sample of community pharmacists in GB. In the next sections, the validity of the instrument is discussed, followed by a discussion of the preliminary findings.

\section{Instrument validity}

The instrument demonstrated good psychometric properties in terms of component structure, reliability and construct validity. Although no studies were found using generic instruments to measure $\mathrm{OC}$ in community pharmacy, a number of studies were found in healthcare settings. Compared to two commonly used measures of OC - OCAI and OCl (Bellot, 2011) - the instrument showed higher internal consistency of $\alpha=0.97$ for the overall scale, and ranging from 0.84 to 0.95 for the subscales. Studies of the OCAI in healthcare reported values ranging from 0.36 to 0.81 (Wakefield et al., 2001), 0.66 to 0.80 (Goodman et al., 2001) and 0.40 to 0.79 (Meterko et al., 2004). Studies of the $\mathrm{OCl}$ in healthcare reported values ranging from 0.73 to 0.91 (Keenan et al., 1998) and 0.68 to 0.85 (Minvielle et al., 2005). Notwithstanding the inability to establish indirect comparisons between these studies and the one reported in this paper, internal consistency for all scales of the instrument described in this paper were consistently high, and suggest that the instrument in this study is able to describe organisational culture in its specific setting (i.e. community pharmacy), which is important for identifying how context-dependent interventions could be designed to target specific domains. 
No studies using the OCAI in healthcare have reported its component validity in terms of percentage of total variance explained. Of those using the $\mathrm{OCl}$, two reported lower percentages of $47.5 \%$ (Keenan et al., 1998) and $47.0 \%$ (Shortell et al., 1991), compared with the total variance explained by the instrument in this study (53.34\%). One study however, reported a higher percentage of total variance explained of $72.6 \%$, despite reporting lower levels of internal consistency (Minvielle et al., 2005). This higher percentage notwithstanding, Minvielle et al.'s study used principal components analysis to validate the $\mathrm{OCl}$, which assumes that all variance is common, and only identifies linear components, not being possible to interpret each item within the components (Field, 2009). The instrument described here was validated using principal axis factoring, a more robust technique compared to principal components analysis; it allows the estimation of the common variance whilst minimising the effects of the unique and error variance when identifying each component (Field, 2009), providing a more reliable theoretical model of the construct. Hence, despite reporting a higher percentage of total variance explained, the instrument used in Minvielle et al.'s study (2008) may be less accurate. Additionally, the instrument described in this paper was designed specifically for community pharmacy, and is expected to be more reliable when measuring $\mathrm{OC}$ in CP than a generic instrument would (Bellot, 2011), and has shown to be capable of capturing specific aspects deemed important by participants to describe OC in community pharmacy in stages I and II of our study, with high levels of construct validity and reliability. These aspects would not have been captured using generic models, precluding opportunities to understand how OC may be linked to job outcomes and patient safety in this setting. For example, aspects of safety and physical environment of the pharmacy store, as described in the items Feel that a safe environment is provided for the patients and Feel that the shop floor looks professional and welcoming to patients, are specific to community pharmacy. Similarly, other aspects as, for example, those described in the items Fell that my pharmacy skills are well utilised and Am able to apply my pharmaceutical knowledge would not have been captured using a generic instrument of OC. This need to develop and validate a specific measure of culture has been evidenced in a previous community pharmacy study, where a measure of safety culture previously developed for use in Primary Care Trusts (Manchester Patient Safety Assessment Framework) was modified and validated for community pharmacy to ensure that its dimensions 
were applicable to this setting (Ashcroft et al., 2005). Hence, while generic models are able to capture aspects that are common across different settings, findings reported in this study provide further support for the need to develop and validate organisational tools that are specific to the measurement of one given setting to capture OC. Without the ability to identify specific key components of OC which may influence job outcomes, it is not possible to: (a) devise strategies and identify ways in which organisational change can be triggered to encourage organisational aspects that are positive, and (b) change organisational aspects that could be improved, thus justifying the development of the instrument for community pharmacy.

\section{Organisational culture in community pharmacy in Great Britain}

In order to achieve success, healthcare organisations need to pay attention to their OC (Konteh et al., 2011). Organisational cultures that are flexible and supportive, with recognised leadership and cohesive teamwork will facilitate change and positive outcomes (Carlström and Ekman, 2012, Kaufman and McCaughan, 2013, Williams et al., 2015, Terzioglu et al., 2016). On the other hand, rigid cultures where support and cooperation are not valued, and where there is ineffective leadership are more resistant to change (Williams et al., 2015) which has a negative impact on the delivery of high standards of care to patients (Terzioglu et al., 2016). It is therefore important to place value in the investigation and measurement of $\mathrm{OC}$ in order to achieve success. Whilst the direct measurement of basic assumptions is not possible (Schein, 1990), these can be directly inferred through the measurement of observable artefacts (e.g. behaviours) and espoused values (e.g. attitudes). The newly validated instrument described in this paper comprises a set of items organised into five dimensions of $\mathrm{OC}$ in community pharmacy. Instrument items measure attitudes and beliefs (i.e. espoused values), providing a snapshot of the OC existing at one given point in time, and hints at the underlying basic assumptions as well as observable artefacts which may influence job outcomes in the workplace. Survey findings produced by the study reported in this paper suggest that some aspects of $\mathrm{OC}$ are more likely to be reported as present than others, with variation occurring in relation to the type of community pharmacy worked in. While some workplaces were reported as demonstrating aspects related to patient contact and safety frequently, other workplaces were viewed by survey respondents as less likely 
to demonstrate these as frequently. Since many of these aspects of OC are important for providing high quality healthcare, it is possible that these reported differences in OC may be related to different healthcare outcomes (Scott et al., 2003b, Scahill, 2008, Scahill et al., 2009), although this will need investigation in further studies to determine.

Quantitative validation of the instrument reported in this paper has shown its robust statistical and predictive power in discerning different cultures existing in different community pharmacies. Additionally, the instrument is capable of capturing organisational characteristics that are unique to community pharmacy and would not be captured using generic $O C$ instruments. Given that preliminary findings suggest that differences in $\mathrm{OC}$ exist across different community pharmacies the instrument developed and validated here could further be used to identify possible aspects of OC that may benefit from targeted interventions for triggering organisational change. This may then improve outcomes for pharmacists, community pharmacy, and ultimately, patients.

\section{Limitations}

The main limitation relates to the sample of participants used to develop the instrument. In Stages I and II, despite taking steps to ensure maximum representativeness of findings by including participants from different backgrounds and experiences of community pharmacy, the snowballing technique may have impacted on the validity of findings. In stage III (cross-sectional survey), although a small sample size used to validate the instrument, measures of sampling adequacy showed that the number of responses obtained was sufficient to produce reliable results. Furthermore, the sample was broadly representative of the population of community pharmacists in Great Britain. However, the small sample size obtained makes it difficult to determine the extent to which findings reflect true organisational cultures existing in community pharmacy in Great Britain. Additionally, the low response-rate obtained also limited the quantitative techniques that could be used for the instrument's validation. Exploratory factor analysis is a robust validation technique, capable of discriminating between significant factors with small sample sizes. Notwithstanding, it cannot discriminate the individual contribution of each item 
to the measurement of the construct. More robust methods (i.e. Item Response Theory methods) can detect individual contribution of items, but would have required a larger sample (DeVellis, 2012). Future studies with larger samples are recommended to further validate the instrument and investigate the contribution of individual items to the measurement of $\mathrm{OC}$ in community pharmacy.

\section{Conclusion}

The identification of $\mathrm{OC}$ is important for developing interventions to lever organisational change and improve the quality and safety of healthcare in community pharmacy. This paper presents the first instrument to measure $\mathrm{OC}$ in community pharmacy, capable of measuring organisational aspects pertaining to the second layer (i.e. espoused values) of OC described by Schein (1990). Using the instrument in future studies will allow the benchmarking of different community pharmacies through: (a) the measurement of espoused values to provide a snapshot of $\mathrm{OC}$ in community pharmacy at any one given point in time; and (b) the identification of different cultures present in community pharmacy and their underlying basic assumptions and observable artefacts, and how each culture identified affects job, pharmacist or patient outcomes, such as job performance, job commitment, involvement, empowerment, satisfaction and turnover, and patient safety.

\section{References}

ASHCROFT, D. M., MORECROFT, C., PARKER, D. \& NOYCE, P. R. 2005. Safety culture assessment in community pharmacy: Development, face validity, and feasibility of the Manchester Patient Safety Assessment Framework. BMJ Quality \& Safety, 14, 417-421.

BELLOT, J. 2011. Defining and assessing organizational culture. Nursing Forum, 46, 29-37.

BRADLEY, F., WAGNER, A. C., ElVEY, R., NOYCE, P. R. \& ASHCROFT, D. M. 2008. Determinants of the uptake of medicines use reviews (MURs) by community pharmacies in England: A multi-method study. Health Policy, 88, 258-68. 
BROWN, K. L., CROWE, S., FRANKLIN, R., MCLEAN, A., CUNNINGHAM, D., BARRON, D., TSANG, V., PAGEL, C. \& UTLEY, M. 2015. Trends in 30-day mortality rate and case mix for paediatric cardiac surgery in the UK between 2000 and 2010. Open Heart, 2, 1-10.

BRYMAN, A. 2006. Integrating quantitative and qualitative research: how is it done? Qualitative Research, 6, 97-113.

CAMERON, K. S. \& QUINN, R. E. 2005. Diagnosing and changing organizational culture: Based on the competing values framework, San Francisco, John Wiley \& Sons.

CARLSTRÖM, E. D. \& EKMAN, I. 2012. Organisational culture and change: implementing person-centred care. Journal of Health Organization and Management, 26, 175-191.

DEVELLIS, R. F. 2012. Scale development: Theory and applications, Sage Publications.

DRUCKMAN, D., SINGER, J. E. \& COTT, H. V. 1997. Enhancing organizational performance, Washington, DC, The National Academies Press.

FIELD, A. 2009. Discovering statistics using IBM SPSS statistics, Sage Publications.

FOWLER JR, F. J. 1995. Improving survey questions: Design and evaluation, Thousand Oaks, Sage Publications.

GOODMAN, E. A., ZAMMUTO, R. F. \& GIFFORD, B. D. 2001. The competing values framework: Understanding the impact of organizational culture on the quality of work life. Organization Development Journal, 19, 58-68.

GRASHA, A. F. \& SCHELL, K. 2001. Psychosocial factors, workload, and human error in a simulated pharmacy dispensing task. Perceptual \& Motor Skills, 92, 53-71.

GROVES, R. M., FOWLER JR, F. J., COUPER, M. P., LEPKOWSKI, J. M., SINGER, E. \& TOURANGEAU, R. 2009. Survey methodology, New Jersey, John Wiley \& Sons.

HANDY, C. 1993. Understanding organizations, Penguin UK.

HASSELL, K., SESTON, E. M., SCHAFHEUTLE, E. I., WAGNER, A. \& EDEN, M. 2011. Workload in community pharmacies in the UK and its impact on patient safety and pharmacists' well-being: A review of the evidence. Health and Social Care in the Community, 19, 561-575. 
HELMS, M. M. \& STERN, R. 2001. Exploring the factors that influence employees' perceptions of their organisational culture. Journal of Management in Medicine, 15, 415-429.

HOPP, T. R., SORENSEN, E. W., HERBORG, H. \& ROBERTS, A. S. 2005. Implementation of cognitive pharmaceutical services (CPS) in professionally active pharmacies. International Journal of Pharmacy Practice, 13, 21-31.

JACOBS, S., ASHCROFT, D. \& HASSELL, K. 2011. Culture in community pharmacy organisations: What can we glean from the literature? Journal of Health, Organisation and Management, 25, 420-454.

JAMBULINGAM, T., KATHURIA, R. \& DOUCETTE, W. R. 2005. Entrepreneurial orientation as a basis for classification within a service industry: The case of retail pharmacy industry. Journal of Operations Management, 23, 23-42.

JUNG, T., SCOTT, T., DAVIES, H. T., BOWER, P., WHALLEY, D., MCNALLY, R. \& MANNION, R. 2009. Instruments for exploring organizational culture: A review of the literature. Public Administration Review, 69, 1087-1096.

KAUFMAN, G. \& MCCAUGHAN, D. 2013. The effect of organisational culture on patient safety. Nursing Standard, 27, 50-56.

KEENAN, G. M., COOKE, R. \& HILLIS, S. L. 1998. Norms and nurse management of conflicts: Keys to understanding nurse-physician collaboration. Research in Nursing \& Health, 21, 59-72.

KENNEDY, N. 2001. The report of the public inquiry into children's heart surgery at the Bristol Royal Infirmary 1984-1995: learning from Bristol. Bristol Royal Infirmary.

KONTEH, F. H., MANNION, R. \& DAVIES, H. T. O. 2011. Understanding culture and culture management in the English NHS: A comparison of professional and patient perspectives. Journal of Evaluation in Clinical Practice, 17, 111-117.

METERKO, M., MOHR, D. C. \& YOUNG, G. J. 2004. Teamwork culture and patient satisfaction in hospitals. Medical care, 42, 492-498.

MiNVIELle, E., DERVAUX, B., RETBI, A., AEGERTER, P., BOUMENDIL, A., JARS-GUINCESTRE, M. C., TENAILLON, A. \& GUIDET, B. 2005. Culture, organization, and management in intensive care: construction and validation of a multidimensional questionnaire. Journal of Critical Care, 20, 126-138. 
NAGAMI, M., TSUTSUMI, A., TSUCHIYA, M. \& MORIMOTO, K. 2010. Job control and coworker support improve employee job performance. Industrial Health, $48,845-51$.

O'CATHAIN, A., MURPHY, E. \& NICHOLL, J. 2008. The quality of mixed methods studies in health services research. Journal of Health Services Research \& Policy, 13, 92-98.

OGBONNA, E. \& HARRIS, L. C. 2000. Leadership style, organizational culture and performance: Empirical evidence from UK companies. The International Journal of Human Resource Management, 11, 766-788.

PEREPELKIN, J. \& FINDLAY, I. M. Year. Autonomy of entrepreneurial community pharmacists and corporate pharmacy managers: A comparative study. In: Proceedings of the Annual Conference of Administrative Sciences Association of Canada (ASAC), 2009 Canada.

PHARMACEUTICAL SERVICES NEGOTIATING COMMITTEE. 2017. About community pharmacy [Online]. Available: http://psnc.org.uk/psncs-work/aboutcommunity-pharmacy/ [Accessed May, 2017].

PHELPS, A., AGUR, M., VASS, L. \& BLAKE, M. 2014. GPhC Registrant Survey 2013: Findings. London: NatCen Social Research.

PHIPPS, D. L. \& ASHCROFT, D. M. 2011. Psychosocial influences on safety climate: Evidence from community pharmacies. British Medical Journal Quality \& Safety, 20, 1062-1068.

PIOCH, E. A. \& SCHMIDT, R. A. 2001. German retail pharmacies: regulation, professional identity and commercial differentiation. Marketing Intelligence \& Planning, 19, 330-340.

ROBERTS, A. S., BENRIMOJ, S. I., CHEN, T. F., WILLIAMS, K. A., HOPP, R. \& ASLANI, P. 2005. Understanding practice change in community pharmacy: a qualitative study in Australia. Research in Social and Administrative Pharmacy, 1, 546-564.

SCAHILL, S. 2008. Involving community pharmacy services by studying organizational theory. Southern Med Review, 1, 17-19.

SCAHILL, S., HARRISSON, J., CARSWELL, P. \& BABAR, Z. 2009. Organisational culture: An important concept for pharmacy practice research. Pharmacy World \& Science, 31, 517-521.

SCHEIN, H. S. 1990. Organizational culture. American Psychologist, 43, 109-119. 
SCHINKA, A. J., VELICER, W. F. \& WEINER, I. B. 2003. Industrial and organizational psychology. Handbook of Psychology. John Wiley.

SCOTT, T., MANNION, R., DAVIES, H. \& MARSHALL, M. 2003a. The quantitative measurement of organizational culture in health care: A review of the available instruments. Health Services Research, 38, 923-945.

SCOTT, T., MANNION, R., MARSHALL, M. \& DAVIES, H. T. O. 2003b. Does organisational culture influence health care performance? A review of the evidence. Journal of Health Services Research \& Policy, 8, 105-117.

SESTON, E. M. \& HASSELL, K. 2009. Pharmacy workforce census 2008: Main findings. London: Royal Pharmaceutical Society of Great Britain.

SHORTELL, S. M., ROUSSEAU, D. M., GILLIES, R. R., DEVERS, K. J. \& SIMONS, T. L. 1991. Organizational assessment in intensive care units (ICUs): Construct development, reliability, and validity of the ICU nurse-physician questionnaire. Medical care, 29, 709-726.

SMITH, F. 2002. Research methods in Pharmacy practice, Pharmaceutical Press.

STREINER, D. L. \& NORMAN, G. R. 2008. Health Measurement Scales: A practical guide to their development and use, Oxford University Press.

TANN, J., BLENKINSOPP, A. \& PLATTS, A. 2001. Teaching and learning at the leading edge: leading edge practitioners in community pharmacy. Management Learning, 32, 163-179.

TERZIOGLU, F., TEMEL, S. \& USLU SAHAN, F. 2016. Factors affecting performance and productivity of nurses: Professional attitude, organisational justice, organisational culture and mobbing. Journal of Nursing Management, $1-10$.

VISCHER, J. C. 2007. The effects of the physical environment on job performance: Towards a theoretical model of workspace stress. Stress and Health, 23, 175184.

WAKEFIELD, B. J., BLEGEN, M. A., UDEN-HOLMAN, T., VAUGHN, T., CHRISCHILLES, E. \& WAKEFIELD, D. S. 2001. Organizational culture, continuous quality improvement, and medication administration error reporting. American Journal of Medical Quality, 16, 128-134.

WILLIAMS, B., PERILLO, S. \& BROWN, T. 2015. What are the factors of organisational culture in health care settings that act as barriers to the 
implementation of evidence-based practice? A scoping review. Nurse Education Today, 35, e34-341. 
Table 1 - Organisational themes identified by thematic analysis of the qualitative interviews and examples of instrument items drafted for the questionnaire

\begin{tabular}{ccc}
\hline $\begin{array}{c}\text { Themes of organisational } \\
\text { culture in community } \\
\text { pharmacy }\end{array}$ & Definition of themes & Examples of instrument items \\
\hline
\end{tabular}

Contact with patients

Company targets

Feedback

Help, support and social

relationships

Communication

Resources available

Workload

Quality of care

Provision of services

Work environment

Knowledge and skill

utilisation

Autonomy

Work-life balance

Training opportunities

Career progression

Rules, policy and change

Entrepreneurial orientation
Opportunities to spend time with patients

Pharmacy targets, flexibility and balance with other tasks

Quality of information provided about pharmacists' work

Being part of a team working towards a common goal

Quality of internal and external communication

Having adequate resources to carry out work

Organisational aspects influencing the ability to cope with the amount of work

Ability to provide services safely

Opportunity to provide services regularly

Social and physical environment of the store

Opportunities to use pharmaceutical knowledge and skills

Ability to plan and organise work, including having control over work

Maintaining a positive work-life balance

Opportunities for receiving regular and appropriate training Opportunities for career advancement

Being aware of, and understanding rules and changes occurring in the store

Drive to move the business forward and standout from competitors
To provide services that put you in contact with patients To feel comfortable about the targets set by your employer To receive constructive feedback about your work

To receive support from your co-workers whenever you need

To have an effective communication network established in your workplace

To have adequate and up-to-date resources

To have enough time to perform each task adequately

To work in a place known for its high standards of delivery of care

To work in a place known for the diverse range of services provided

To work in a friendly environment

To be able to use your pharmacy knowledge

To be able to plan your work the way you think is best

To have a good work-life balance

To have opportunities for training readily available

To have opportunities for promotion

To work in a place with transparent policies and rules

To adapt to new demands of the market easily 
Table 2 - Dimensions of organisational culture in community pharmacy

\begin{tabular}{|c|c|}
\hline $\begin{array}{l}\text { Dimension of OC in } \\
\text { community pharmacy }\end{array}$ & Definition \\
\hline $\begin{array}{l}\text { Business and work } \\
\text { configuration (20 Items) }\end{array}$ & $\begin{array}{l}\text { Aspects relating to workload, management style, communication, } \\
\text { including being listened to, support at work, autonomy in decision-making } \\
\text { and the degree of flexibility allowed in how work is approached. This } \\
\text { dimension also describes the business orientation established in each } \\
\text { pharmacy (e.g. the extent to which the OC prioritises patient care over } \\
\text { financial reward). }\end{array}$ \\
\hline $\begin{array}{l}\text { Social relationships (16 } \\
\text { Items) }\end{array}$ & $\begin{array}{l}\text { The quality of workplace relationships and the dynamics of the social } \\
\text { context are described by this dimension. It measures characteristics } \\
\text { including team cohesiveness, and shared professional values and } \\
\text { objectives that may impact on the delivery of care. }\end{array}$ \\
\hline $\begin{array}{l}\text { Personal and professional } \\
\text { development (11 Items) }\end{array}$ & $\begin{array}{l}\text { Opportunities for career progression, and the availability of training for } \\
\text { improving and updating clinical knowledge and skills provided by the } \\
\text { organisation. Behavioural norms related to how the organisation copes } \\
\text { with change, and feedback for improving the delivery of care. }\end{array}$ \\
\hline
\end{tabular}

\section{Example of instrument items}

Feel that the company will not blame me if I do not reach the targets

Receive help and support immediately when I need it

Am able to plan my work the way I think is best

Can discuss work-related issues openly with other members of staff

Am able to resolve conflicts with my co-workers easily

Feel that my professional values are shared by my co-workers

Am provided with a varied range of training opportunities

Receive support if I want to improve my skills

Have opportunities for promotion 
Table 2 - Dimensions of organisational culture in community pharmacy (cont.)

\begin{tabular}{|c|c|c|}
\hline $\begin{array}{l}\text { Dimension of OC in } \\
\text { community pharmacy }\end{array}$ & Definition & Example of instrument items \\
\hline \multirow{3}{*}{ Skills utilisation (6 Items) } & \multirow{3}{*}{$\begin{array}{l}\text { Aspects of workload (e.g. nature and diversity of tasks and frequency of } \\
\text { contact with patients) and those measuring professional knowledge and } \\
\text { clinical skills used in undertaking work. }\end{array}$} & Feel that my pharmacy skills are well utilised \\
\hline & & Have a job that is not monotonous \\
\hline & & Am able to apply my pharmaceutical knowledge \\
\hline \multirow{3}{*}{$\begin{array}{l}\text { Environment and structures } \\
\text { (7ltems) }\end{array}$} & \multirow{3}{*}{$\begin{array}{l}\text { Professional behaviours and workplace facilities, in association with the } \\
\text { quality and safety of services provided and resources available to handle } \\
\text { workload. }\end{array}$} & Work in a clean and tidy environment \\
\hline & & $\begin{array}{l}\text { Feel that a safe environment is provided for the } \\
\text { patients }\end{array}$ \\
\hline & & $\begin{array}{l}\text { Feel that a safe environment is provided for the } \\
\text { staff }\end{array}$ \\
\hline
\end{tabular}


Table 3 - Dimensions of organisational culture in community pharmacy in Great Britain

\begin{tabular}{|lcccc|}
\hline \multicolumn{1}{|c}{ Dimensions } & $\begin{array}{l}\text { Number } \\
\text { of items }\end{array}$ & Mean & SD & Cronbach's $\alpha$ \\
\hline $\begin{array}{l}\text { Business and } \\
\text { work configuration }\end{array}$ & 20 & 3.49 & 1.15 & 0.95 \\
$\begin{array}{l}\text { Social } \\
\text { relationships }\end{array}$ & 16 & 4.05 & 0.94 & 0.93 \\
$\begin{array}{l}\text { Personal and } \\
\text { professional } \\
\text { development }\end{array}$ & 11 & 3.33 & 1.17 & 0.91 \\
$\begin{array}{l}\text { Skills utilisation } \\
\text { Environment and }\end{array}$ & 6 & 3.86 & 0.97 & 0.84 \\
structures & 7 & 3.98 & 0.95 & 0.84 \\
\hline
\end{tabular}

